\title{
Study of the Behavior of Beam due to the Variation in Strength of Concrete and Steel Bars
}

\author{
Al Amin, Md. Shamim Al Razib \\ Department of Civil Engineering, Rajshahi University of Engineering \& Technology, Rajshahi, Bangladesh \\ Email address: \\ Aalaminruet10@gmail.com (Al Amin), Shamimrazib.ruet@gmail.com (Md. S. A. Razib) \\ To cite this article: \\ Al Amin, Md. Shamim Al Razib. Study of the Behavior of Beam due to the Variation in Strength of Concrete and Steel Bars. Urban and \\ Regional Planning. Vol. 3, No. 1, 2018, pp. 6-10. doi: 10.11648/j.urp.20180301.12
}

Received: October 29, 2017; Accepted: December 1, 2017; Published: January 19, 2018

\begin{abstract}
RCC structures are primarily based with beams and columns. In general, the compressive strength of concrete and the yield strength of steel are specified in the design process. Compressive strength of concrete depends on a number of factors and generally shows some degree of variation from the desired strength. On the other hand, reinforcing bars with higher yield strength than that recommended in the Bangladesh National Building Code is available in the market and being used in construction. So, in practical cases, after casting the compressive strength as well as the tensile strength are not generally achieved as desired. Therefore, increase in yield strength of steel and decrease in compressive strength of concrete may have adverse effects on the flexural behavior of beams. This study includes the behavior of reinforced concrete beam due to this variation in strengths. This study shows that how certain beam behaves due to the variation of strength. Besides, reduction in ductility is also observed due to strength variation in the properties of the major constituent materials. A complete theoretical analysis along with some experimental investigation is presented in this paper.
\end{abstract}

Keywords: Ductility, High-Strength Steel, Bangladesh National Building Code (BNBC), Beam Behavior

\section{Introduction}

Along with most of the countries Bangladesh also prefers reinforced concrete (RC) building frames in building constructions where beam plays a vital role. Recent earthquakes as well as some tragic incidents have raised the issue of performance of these buildings during an earthquake or under ultimate load. Concrete and reinforcing bars are the chief constituent materials in RC buildings. Since reinforcing bars are made in the factory its quality can be easily controlled and high strength steel bars are also available in the local market. The use of high-strength steel bars offers several advantages, such as the reduction of the reinforcement ratio, less cost for reinforcement placement, reduced reinforcement congestion, better concrete placement etc. $[8,9,10]$. On the other hand the quality of concrete is difficult to control and this job has become an impossible one in Bangladesh because of the crude construction technology and no-trained workers. Another important issue is the use of higher strength steel than that specified in the Bangladesh National Building Code (BNBC). BNBC adopted some of the ASTM Standards for structural steel and allowable yield strength of steel reinforcing bars was limited to $410 \mathrm{MPa}(60$ ksi) [3]. According to ASTM A615/A615M-09 bars are of three minimum yield strength levels: namely, 40000 [280 $\mathrm{MPa}$ ], 60000 [420 MPa], and $75000 \mathrm{psi}[520 \mathrm{MPa}$, designated as Grade 40 Grade 60 and Grade 75 respectively [2]. The important concern is that RC members are designed with Code specified maximum yield strength of $410 \mathrm{MPa}$ and constructed with locally available higher grade steels such as thermo mechanically treated (TMT) high strength structural steel bars having yield strength up to $500 \mathrm{MPa}$ or $72.5 \mathrm{ksi}$ [4]. Therefore such increase in yield strength of steel and decrease in compressive strength of concrete may have adverse effects on the behavior of RC flexural members and the beam would not achieve adequate ductility under ultimate load. This study aims to focus on

1. the behavior of beams using TMT high strength structural steel bars and concrete having specified design strength.

2. the behavior of beams using TMT high strength structural steel bars and concrete having strength less than the specified design strength. 


\section{Methodology}

The study is divided into two steps (i) analytical study with some typical beam sections (ii) experimental investigations. In each case ultimate load carrying capacity of the beam and ductility was measured.

Ductility is an important issue in the design of structure and structural member and is defined as the ability of the material/member to sustain deformation beyond the elastic limit while maintaining a reasonable load carrying capacity until total failure [6]. Ductility is a valuable structural property as it allows stress redistribution and provides warning of impending failure. The ductility of a reinforced concrete beam depends on the amount of tension reinforcement, the amount of compression reinforcement and the strength and ductility of the materials used [7].

Generally, reinforced concrete beams are under-reinforced by design, so that failure is initiated by yielding of the steel reinforcement, followed, after considerable deformation at no substantial loss of load carrying capacity, by concrete crushing and ultimate failure. That is a ductile mode of failure is desired and is ensured by designing the tensile reinforcement ratio to be substantially below the balanced ratio, which is the ratio at which steel yielding and concrete crushing occur simultaneously.

The mathematical expression of balanced reinforcement ratio [5] is

$$
\rho_{b}=0.85 \beta_{1} \frac{f^{\prime} c}{f_{y}} \frac{\epsilon_{u}}{\epsilon_{u}+\epsilon_{y}}
$$

where,

$\rho_{b}=$ balanced reinforcement ratio

$f^{\prime}{ }_{c}=$ compressive strength of concrete,

$f_{y}=$ yield strength of steel,

$\epsilon_{u}=$ ultimate strain in concrete (usually taken as 0.003 ),

$\epsilon_{y}=$ yield strain of steel and

$\beta_{1}=$ constant depends on compressive strength of concrete. It is clear from Eq. (1) that for a particular beam section the balanced reinforcement ratio depends on the material properties. Besides upper limit of the reinforcement ratio has been introduced in the design Codes (e.g. ACI 31805) to guarantee ductility

$$
\rho_{\text {max }}=0.85 \beta_{1} \frac{f^{\prime} c}{f_{y}} \frac{\epsilon_{u}}{\epsilon_{u}+0.004}
$$

The reinforcement ratio thus provides a measurement for ductility and the ductility corresponding to the maximum allowable reinforcement ratio provides a measure of the minimum acceptable ductility. The mode of failure is another important issue which is defined as a function of net tensile strain. The net tensile strain is the tensile strain in the extreme tension steel at nominal strength. According to ACI Code (2005), a beam section is said to be tension-controlled if the net tensile strain is equal to or larger than 0.005 and compression-controlled if the net tensile strain is equal to or less than 0.002 [1]. A section is in a transition region between compression- and tension-controlled sections.
In this article the curvature ductility was considered. The ductility factor was taken as the ratio of the curvature at yield and ultimate condition. The ductility can be estimated as shown in Figure 1.
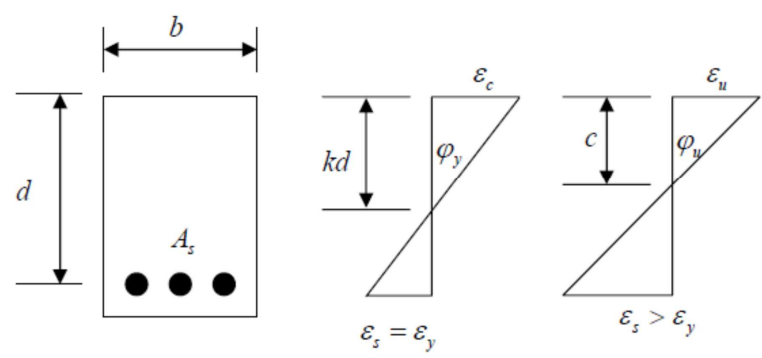

Figure 1. Calculation of ductility.

$$
\text { The curvature at yield condition, } \varphi_{\mathrm{y}}=\frac{\mathrm{f}_{\mathrm{y}}}{\mathrm{E}_{\mathrm{s}}} \frac{1}{\mathrm{~d}(1-\mathrm{k})}
$$

where, $\varphi_{\mathrm{y}}=$ curvature at yield condition, $k=$ constant, $E_{s}=$ modulus of elasticity of steel, $d=$ effective depth of the beam.

The curvature at ultimate condition, $\varphi_{\mathrm{u}}=\frac{\varepsilon_{\mathrm{u}}}{\mathrm{c}}=\frac{\varepsilon_{\mathrm{u}} \beta_{1}}{\mathrm{a}}$

where, $\varphi_{\mathrm{u}}=$ curvature at ultimate condition, $a=$ depth of rectangular compression stress block.

$$
\text { Ductility } \mu=\frac{\varphi_{\mathrm{u}}}{\varphi_{\mathrm{y}}}=\frac{\varepsilon_{\mathrm{u}}}{\mathrm{f}_{\mathrm{y}} / \mathrm{E}_{\mathrm{s}}} \frac{\mathrm{d}(1-\mathrm{k})}{\mathrm{a} / \beta_{1}}
$$

Another important factor, the strength reduction factor, is also incorporated in the design of the reinforced concrete members which is essentially based on the deformation capability of the member. The strength reduction factor depends on the net tensile strain of the beam. The purposes of the strength reduction factor are (1) to allow for the probability of under-strength members due to variations in material strengths and dimensions (2) to reflect the degree of ductility and required reliability of the member under the load effects being considered and (3) to reflect the importance of the member in the structure [1] Design strength or usable strength of a member or cross section is the nominal strength multiplied by the strength reduction factor.

\section{Theoretical Analysis}

To understand the effect of the variation in chief constituent materials a numerical analysis was conducted on a beam section. A typical beam section (width $=12$ inch, overall depth $=26$ inch, effective depth $=22.5$ inch) reinforced with three No.7 and two No. 9 bars was considered and analyzed. The analyses results are presented in Table 1. The beam section was analyzed considering two different grades of concrete to understand how the material 
strength affects the behavior of reinforced concrete beams. Balanced steel ratio, maximum steel ratio and ductility were calculated for each beam using the equations shown in the previous section and are presented in Table 1.

Table 1. Numerical analysis results.

\begin{tabular}{|c|c|c|c|c|c|c|c|}
\hline Sl. No. & $f^{\prime}{ }_{c}(\mathrm{ksi})$ & $f_{y}(\mathrm{ksi})$ & Steel ratio & Balanced steel ratio & Max. steel ratio & Net tensile strain & Strength reduction factor \\
\hline A1 & 3.0 & 60.0 & 0.014 & 0.0214 & 0.0155 & 0.0050 & 0.90 \\
\hline $\mathrm{A} 2$ & 3.0 & 72.5 & 0.014 & 0.0163 & 0.0128 & 0.0033 & 0.76 \\
\hline A3 & 2.5 & 72.5 & 0.014 & 0.0136 & 0.0107 & 0.0024 & 0.68 \\
\hline B1 & 4.0 & 60.0 & 0.014 & 0.0285 & 0.0206 & 0.0077 & 0.90 \\
\hline B2 & 4.0 & 72.5 & 0.014 & 0.0217 & 0.0171 & 0.0059 & 0.90 \\
\hline B3 & 3.5 & 72.5 & 0.014 & 0.0190 & 0.0150 & 0.0048 & 0.69 \\
\hline
\end{tabular}

Table 1. Continued.

\begin{tabular}{lllll}
\hline Sl. No. & Mode of failure & Ductility & Nominal Moment Capacity (k-ft) & Ultimate Moment Capacity (k-ft) \\
\hline A1 & Tension & 2.24 & 356.7 & 321.0 \\
A2 & Transition & 1.53 & 413.2 & 315.0 \\
A3 & Transition & 1.24 & 392.5 & 265.0 \\
B1 & Tension & 3.07 & 374.4 & 337.0 \\
B2 & Tension & 2.10 & 439.0 & 395.1 \\
B3 & Transition & 1.79 & 428.0 & 295.0 \\
\hline
\end{tabular}

It is clear from Table 1 that the nominal strength of the beam increases as the yield strength of steel increases (Beams A2 and B2). However, the ultimate strength or the design strength of the beam may not increase in each case because the net tensile strain reduces appreciably. On the other hand, ductility of the member reduces with the inclusion of higher strength steel than that was primarily specified in the design. The minimum ductility may be obtained if the compressive strength of concrete decreases and the yield strength of the steel increase (Beams A3 and B3). The reduction in ductility is obvious and irrespective of concrete grade. Similarly, the net tensile strain reduces as the yield strength of the steel increases or the compressive strength of concrete reduces. Balanced steel ratio or the maximum steel ratio also decreases the yield strength of the steel increases or the compressive strength of concrete reduces.

\section{Experimental Investigation}

To make the analysis more reliable, an experimental program was taken. Three rectangular singly reinforced concrete beams having dimensions 4in. $x$ 10in. $x$ 48in. (breadth $\mathrm{x}$ depth $\mathrm{x}$ length) were fabricated for testing. The beams were cast from normal strength concrete with cylinder compressive strength ranging from 2500 to 3000 psi. In order to study the effects of different materials strength yield strength of steel was also varied. The main bars (two No. 4 bars) were placed near the bottom of the beams. Near the top of the beams, two No. 3 bars $(8 \mathrm{~mm})$ bars were added as hanger bars for fixing the stirrups. All of the beams were simply supported at a span of $42 \mathrm{in}$. and were tested by subjecting them to monotonically applied point load at midspan, as illustrated in Figure 2. Detailed properties of the beams are given in Table 2. During loading, the vertical deflections at mid-span of the beams were measured by a displacement dial gauge. Visual inspection of the cracks was carried out throughout the tests. The test was terminated when the specimen failed completely, i.e. when the resistance of the specimen dropped. The failure patterns are shown in Figure 3 .

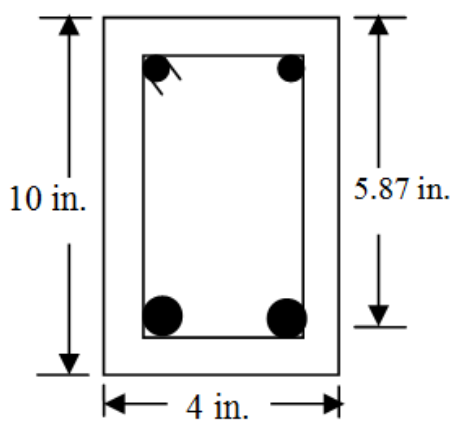

(a) Beam cross

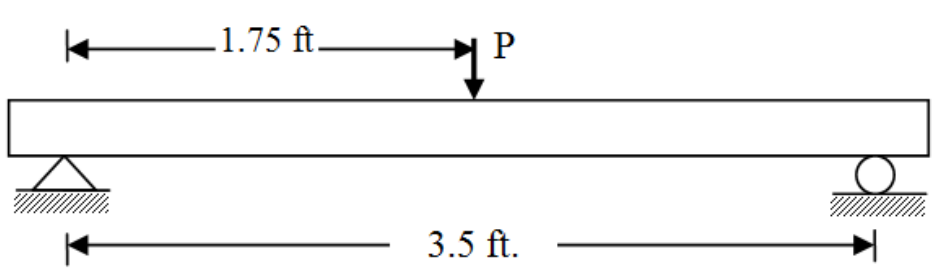

(b) Loading arrangement

Figure 2. Beam cross section and loading arrangement. 

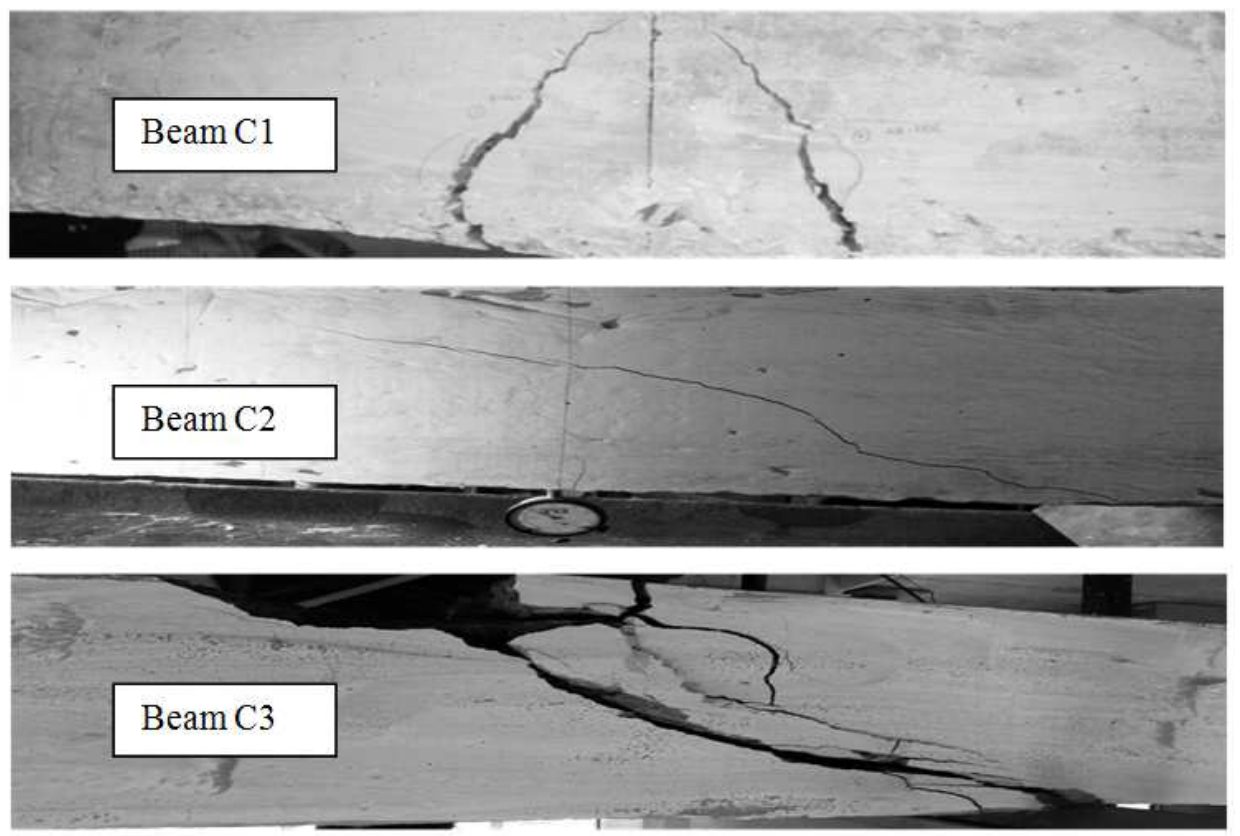

Figure 3. Failure pattern of experimental beams.

Table 2. Properties of the beam specimen.

\begin{tabular}{llllll}
\hline Sl. No. & $\boldsymbol{f}^{\prime}{ }_{\boldsymbol{c}}(\mathbf{k s i})$ & $\boldsymbol{f}_{\boldsymbol{y}}$ (ksi) & Balanced steel ratio & Max. steel ratio & Net tensile strain \\
\hline C1 & 2.93 & 60.0 & 0.021 & 0.0151 & 0.0053 \\
C2 & 2.97 & 72.5 & 0.016 & 0.0127 & 0.0040 \\
C3 & 2.52 & 72.5 & 0.014 & 0.0108 & 0.0029 \\
\hline
\end{tabular}

Table 2. Continued.

\begin{tabular}{llllll}
\hline Sl. No. & Strength reduction factor & Mode of failure & Ductility & Deflection (in) & Ultimate Load (k) \\
\hline C1 & 0.90 & Tension & 2.51 & 0.26 & 10.5 \\
C2 & 0.66 & Transition & 1.74 & 0.18 & 12.1 \\
C3 & 0.61 & Transition & 1.44 & 0.14 & 12.5 \\
\hline
\end{tabular}

\section{Experimental Results}

The experimental program was designed in such a way that the variation of the material strengths on the behavior of beam can be studied. From the numerical study results it is clear that a section may turn into over-reinforced if the strength of concrete decreases or strength of steel increases. Therefore, the tension reinforcement may or may not yield before the concrete in the compression zone is crushed. If the strength of the materials remains the same as it was considered in the design the reinforcement ratio may lie below the allowable maximum amount as a result the tension reinforcement will yield before the concrete is crushed and the beam will fail in a ductile manner. If the reinforcement ratio becomes larger than the allowable maximum, the concrete will be crushed without prior yielding of the tension reinforcement and the beam will fail in a brittle manner.

Beam $\mathrm{C} 1$ was designed considering compressive strength of 3000 psi and yield strength of steel as 60,000 psi. Due to some limitations, measurement of strain of steel or concrete was not possible. It was expected from the previous numerical study that the use of higher strength steel or lower strength concrete will affect the behaviour of the beam significantly. From the experiment the ultimate load capacity of the beam was measured as 10.5, 12.1 and 12.5 kips for beam $\mathrm{C} 1, \mathrm{C} 2$ and $\mathrm{C} 3$ respectively. It is evident that the load carrying capacity of the beam has been increased after increasing the yield strength of steel. However, the ultimate load of beam C3 was larger than the expected. It is noteworthy that the deflection of the beam specimens reduces as the yield strength of steel increases or compressive strength of concrete decreases. The measured deflections are well correlated with the theoretical ductility. It is evident from the analytical study that there is a remarkable effect on the mode of failure of the beam and the beam which was initially designed as an under-reinforced section may turn into an over-reinforced section i.e. the beam may also fail by crushing of concrete instead of yielding of steel. The experimental beam also reflects the same as it can be seen from Figure 3.

\section{Conclusion}

In the design of a reinforced concrete beam, both the flexural strength and ductility need to be considered. However, more importance is usually given to the flexural 
strength and only a simple check is carried out to ensure that a certain minimum level of ductility is provided by keeping the beam under-reinforced. From the structural safety point of view, ductility is as important as strength. A good ductility would provide the beam with a much better chance of survival when it is overloaded, attacked by a severe earthquake or subjected to an accidental impact.

From the above, it is evident that the major factors affecting the flexural strength and ductility of a reinforced concrete beam section are the concrete grade, yield strength of steel and tension steel ratio. In the case of a singly reinforced section, at a fixed concrete grade, the use of a higher tension steel ratio leads to a higher flexural strength but a lower ductility. Hence, the increase in flexural strength is achieved by compromising ductility.

When specified design strength and actual strength remain the same, then the steel ratio is below the allowable maximum steel ratio thus beam shows tension failure and produce higher deflection and ductility. When compressive strength remain the same but steel strength is increased, then beam shows larger nominal strength and produces relatively lower deformation and ductility. In case compressive strength is decreased but steel strength is increased which may be a common case in Bangladesh, the steel ratio increases and mode of failure of the beam is also changed and results lower deformation and ductility.

\section{Acknowledgements}

Gratefully acknowledges our profound gratitude and indebtedness to our guide Dr. N. H. M Kamrujjaman Serker. Author also gradually acknowledge towards all teachers of Department of Civil Engineering, Rajshahi University of Engineering \& Technology; and all lab assistants, who helped and suggested to accomplish this study.

\section{References}

[1] ACI Committee 318. (2005). Building Code Requirements for Structural Concrete (ACI 318-05) and Commentary, American Concrete Institute, Farmington Hills, MI.

[2] ASTM A615/A615M-09. (2009). Standard Specifications for Deformed and Plain Carbon-Steel Bars for Concrete Reinforcement, ASTM International, West Conshohocken, PA.

[3] Bangladesh National Building Code. (1993). Housing and Building Research Institute. Dhaka, Bangladesh.

[4] Islam, M. (2010). "Thermo Mechanically Treated Advanced Steels for Structural Applications." Proceedings of 2010 MARTEC International Conference of Merine Technology in Dhaka, December 11th-12th, Bangladesh.

[5] Nilson, S. H., Darwin, D., \& Dolan, C. (2004). Design of Concrete Stuctures, Thirteenth edition, McGraw Hill.

[6] Pam, H., Kwan, A., \& Islam, M. (2001). "Flexural Strength and Ductility of Reinforced Normal- and High-Strength Concrete Beams." Proceedings of the Institution of Civil Engineers: Structures and Buildings, 146(4), 381-389.

[7] Sarkar, S., Adwan, O., \& Munday, J. (1997). "High Strength Concrete: An Investigation of the Flexural behaviour of High Strength RC Beams." Structural Engineer, 75(7), 115-121.

[8] S.H. Alsayed \& A.M. Alhozaimy (1999). Ductility of concrete beams reinforced with FRP bars and Steel fibers, J. Compos. Mater. 33(19), 1792-1806.

[9] M.A. Aiello, L. Ombres. (2002). Structural performances of concrete beams with hybrid fiber-reinforced polymer steel reinforcements, J. Compos. Constructr. 6, 133-140.

[10] A. Nanni, A. De Luca and H.J. Zadeh (2014). Reinforced concrete with FRP bars mechanics and design, Taylor and Francis Group, USA. 